exposure to flour dust and wood dust, but not to natural or artificial textile fibres. A consistent inverse risk was observed for Bcell lymphoma (OR $=0.6,95 \%$ CI $0.3-1.0)$, and it was likewise for its major subtypes, namely diffuse large cell lymphoma (DLBCL), follicular lymphoma (FL) and chronic lymphocytic leukaemia (CLL). Age $<=18$ at first exposure conveyed a further decrease in lymphoma risk (OR $=0.5,95 \%$ CI 0.2-1.2).

Conclusions Although with interpretative limitations due to the small study size, our results suggest that exposure to flour dust and wood dust might contribute a reduction in risk of malignant lymphoma.

\section{FACTORS ASSOCIATED WITH THE USE OF HEARING PROTECTION DEVICE AT WORK}

${ }^{1}$ Tatiane Meira, ${ }^{2}$ Vilma Santana, ${ }^{1,2}$ Silvia Ferrite. ${ }^{1}$ Department of Speech-LanguageHearing Sciences, UFBA, Salvador, Bahia, Brazil; ${ }^{2}$ Institute of Collective Health, UFBA, Salvador, Bahia, Brazil

\subsection{6/oemed-2014-102362.306}

Objectives To identify factors associated with hearing protection device use (HPD) at work.

Methods This is a cross-sectional study carried out with a random cluster area sample of households from the city of Salvador, Bahia, Brazil. Questionnaires were used to obtain sociodemographic, occupational and health related data. Noise exposed worker were those who reported having to shout to be heard in the workplace. When exposed, they were asked whether they use HPD, and how often was it.

Results There were 2429 workers from 18 to 65 years of age, and $299(12.3 \%)$ reported being exposed to loud noise at work. The prevalence of HPD use was 44.5\%, 59.3\% and 21.4\% for men and women, respectively. Among men, only high socioeconomic status (prevalence ratio, $\mathrm{PR}=1.47 ; 95 \%$ confidence interval, CI: $1.14,1.90)$ and previous audiometry $(\mathrm{PR}=1.47 ; 95 \%$ CI: $1.15,1.88)$ were associated with HPD use. In contrast, among women the perception of a good safety climate was associated with HPD use (PR=2.92; 95\% CI: 1.34, 6.34), particularly the reporting of having supervisors committed with safety $(\mathrm{PR}=2.09$; 95\% CI: 1.04, 4.21), clear rules to prevent workrelated injuries $(\mathrm{PR}=2.81 ; 95 \% \mathrm{CI}: 1.41,5.59)$ and when they were informed about work safety guidelines $(\mathrm{PR}=2.42 ; 95 \% \mathrm{CI}$ : 1.23, 4.76).

Conclusions Our results show that there is a gender bias regarding HPD use less favourable to women compared with men; women's HPD use is more likely to be positively influenced by safety climate suggesting that gender needs to be taken into account in hearing protection programs.

\section{OCCUPATIONAL NOISE EXPOSURE AND THE PREVALENCE OF HYPERGLYCEMIA}

${ }^{1}$ Tzu-Yi Yu, ${ }^{2}$ Chiu-Shong Liu, ${ }^{1}$ Li-Hao Young, ${ }^{1}$ Ta-Yuan Chang. ${ }^{1}$ China Medical University, Taichung, Taiwan; ${ }^{2}$ China Medical University Hospital, Taichung, Taiwan

\subsection{6/oemed-2014-102362.307}

Objectives This cross-sectional study aimed to investigate the association between occupational noise exposure and the prevalence of hyperglycemia among workers.

Method We recruited 532 volunteers in a machinery and equipment manufacturing factory as the study population in Central
Taiwan. The walk-through survey was performed to identify the workplaces with noise levels above $80 \mathrm{~A}$-weighted decibel (dBA) first and then the noise dosimeter was used to conduct personal time-weighted-average sound levels. After assigning each subject to a similar exposure group, we classified all subjects into highexposure (noise levels $\geq 85 \mathrm{dBA}, \mathrm{n}=91$ ), median-exposure $(80 \leq$ noise levels $<85 \mathrm{dBA}, \mathrm{n}=62$ ), low-exposure (noise levels $<80 \mathrm{dBA}, \mathrm{n}=76$ ) and reference groups (officers, $\mathrm{n}=303$ ). Logistic regressions were applied to estimate the risk of hyperglycemia by different exposure groups after controlling for potential confounders.

Results The mean noise levels of high-exposure, median-exposure, low-exposure and office workers were $89.5 \pm 2.90 \mathrm{dBA}$, $83.4 \pm 0.4 \mathrm{dBA}, 76.7 \pm 1.1 \mathrm{dBA}$ and $71.4 \pm 4.0 \mathrm{dBA}$, respectively, and there was a significant difference between groups $(\mathrm{p}<$ 0.001). The prevalence of hyperglycemia among high-exposure, median-exposure, low-exposure and office workers were 10.2\%, 13.2\%, 11.3\% and 9.9\%, respectively. After controlled for age, sex, education level, body mass index, cigarette smoking, alcohol drinking and regular exercise, the odds ratio of hyperglycemia between the high-exposure and office workers was 3.96 (95\% confidence interval $=0.83-18.83)$, which had a marginal difference $(\mathrm{p}=0.08)$.

Conclusions Occupational noise exposure above $85 \mathrm{dBA}$ might be associated with the increasing prevalence of hyperglycemia. Future studies should be conducted to demonstrate the potential causality of occupational noise and hyperglycemia.

\section{AN ERGONOMIC ASSESSMENT: OCCUPATIONAL HEALTH AND SAFETY RISK FACTORS OF COMMERCIAL CAFETERIA WORKERS}

Hema Bhatt, Promila Sharma. G. B. Pant University of Agriculture and Technology, Pantnagar, Uttarakhand, India

\subsection{6/oemed-2014-102362.308}

Objectives Kitchen work is demanding, both physically and mentally. The employees work under pressure of time and perform various parallel tasks, many of which include exposure to a combination of risk factors of MSDs. This study was conducted for ergonomic assessment of commercial kitchen workers working in university hostel cafeteria

Method A survey of 40 workers employed at university hostel cafeteria at G. B Pant University of Agriculture and Technology at Uttarakhand state in India was carried out. Self administered questionnaire, interviews and observations were used as research instruments to collect data.

Results It was found that there exists some major risk factors including repetition, awkward postures, force exertion, static posture, mechanical contact stress, temperature and vibration at these commercial kitchen workstation. 77.5 percent respondents were found to be involved in 5-8 h, 15 per cent of respondent were found to be involved for $9-12 \mathrm{~h}$ and 7.5 percent of the respondents were found working for 13-16 h. Nearly all the workers felt pain in neck, shoulders, wrist, elbow, knee, and ankle, upper and in lower back.

Conclusions An ergonomically designed workstation reduces the human efforts, enhances the work efficiency and at the same time provides the safety to the worker. Kitchen workers should be given awareness about the advantages and disadvantages of the good ergonomic practices so as to reduce the occupational health hazards and increase productivity. 